\title{
NONDIGESTIVE CELL TYPES IN THE MIDGUT EPITHELIUM OF RHODNIUS PROLIXUS (HEMIPTERA: REDUVIIDAE) ${ }^{1}$
}

\author{
P.F. Billingsley ${ }^{2,3}$ and A.E.R. Downe ${ }^{2}$
}

\begin{abstract}
The ultrastructure of regenerative cells and endocrine cells in the midgut epithelium of mated female Rhodnius prolixus is described. Regenerative cells are numerous, found in all midgut regions, and do not contain any of the normal secretory apparatus of a cell. Endocrine cells are less numerous, restricted to the intestine, and contain prominent Golgi complexes, electron-opaque vacuoles, and intermediate-staining secretory granules. Both cell types rest on the basal lamina of the midgut and are considerably smaller than the normal digestive epithelial cells. The structure of the endocrine cells is compared to those from other insects, and a role for the endocrine cell in the hormonal control of blood meal digestion is postulated.
\end{abstract}

The digestive epithelial cells of the midgut of Rhodnius prolixus Stål have been previously described in mated females (Billingsley \& Downe 1983), 5th-instar nymphs (Pacheco \& Ogura 1966; Pacheco 1970), and 2nd- and 3rd-instar nymphs (Bauer 1981). While these cells exhibit the gross structure and organization typical of an insect midgut epithelium (for reviews see Andries 1982; Martoja \& Ballan-Dufrancais 1982), the midgut cells of Rhodnius and other Hemiptera do possess some unusual ultrastructural modifications (Burgos \& Gutierrez 1976; Gutierrez \& Burgos 1978; Lane \& Harrison 1979; Andries \& Torpier 1982; Baerwald \& Delcarpio 1983), some of which are produced in response to a blood meal (Bauer 1981; Billingsley \& Downe 1983, 1985). It has been noted that, unlike many other insect groups (Anderson \& Harvey 1966; de Priester 1971; Reinhardt 1976), the midgut of Rhodnius displays little evidence of specialization into functional cell types.

This paper describes cell types found in the midgut epithelium of Rhodnius that do not appear to be directly involved in the digestive process and therefore have not been described in previous papers.

\section{MATERIALS AND METHODS}

Rhodnius prolixus was maintained as described by Kwan \& Downe (1977), and mated females were

1. These studies were supported by a grant from the Natural Sciences and Engineering Research Council of Canada.

2. Department of Biology, Queen's University, Kingston, Ontario K7L 3N6, Canada. Send reprint requests to this address.

3. Present address: Swiss Tropical Institute, Socinstrasse 57, CH 4051, Basel, Switzerland. obtained by the method of Houseman \& Downe (1983). Insects were fed, dissected, and their midguts prepared for electron microscopy as previously described (Billingsley \& Downe 1983). Sections from the anterior midgut, anterior intestine, and posterior intestine (Wigglesworth 1943) taken from mated females at various times after feeding were scanned for nondigestive cells. A total of 47 grids, each holding 3-8 sections, was examined. Two nondigestive cell types were consistently observed.

\section{RESULTS}

\section{Regenerative cells}

Regenerative cells were found singly (Fig. 1) or in pairs (Fig. 2, 3) in all 3 midgut regions. These were typically small, inconspicuous cells resting upon the basal lamina. The basal plasma membrane was apposed to the basal lamina rather than folded into a basal labyrinth, and these cells never possessed a surface exposed to the midgut lumen. The small nucleus occupied most of the cell volume, while mitochondria, free ribosomes, and short strands of rough endoplasmic reticulum ( $\mathrm{rER}$ ) were the only organelles found in the cytoplasm. Neither lysosomes nor Golgi complexes were observed in the regenerative cells. These cells were common in the midgut epithelium, and usually $1-5$ cells could be found in any random cross section of the midgut. No mitotic activity was observed.

\section{Gut endocrine cells}

Gut endocrine cells (Fig. 4) were found only in the intestinal region of the midgut and were not common in the midgut epithelium; they were not detectable in most random cross sections, although up to 3 cells could be observed in 1 section. These cells also rested upon the basal lamina, had no basal labyrinth, and no surface exposed to the midgut lumen. The endocrine cells were characterized by the presence of secretory vesicles of intermediate density, usually concentrated in the basal region of the cytoplasm (Fig. 5), and often by larger, electron-opaque vacuoles in the apical region of the cytoplasm (Fig. 6). Golgi complexes were always 
numerous, conspicuous, and well defined. Mitochondria, free ribosomes, and rER were always present, and degenerative, myelinlike figures were sometimes observed. Secretory vesicles were most common close to the basal plasma membrane, but no fusion of the vesicular membrane with the basal plasma membrane was observed.

\section{DISCUSSION}

The regenerative cells in the midgut of mated female Rhodnius were similar to those described from earlier stages of Rhodnius (Bauer 1981) and from other diverse species (Martoja \& Ballan-Dufrancais 1982), although they were never seen in conspicuous regenerative "nests" common in many insect groups. As mitotic activity was never observed after a blood meal, it is presumed that feeding does not induce proliferation of the epithelium. Conversely, the occurrence of some paired regenerative cells suggested that some cell generation and/or replacement continues throughout the adult stage.

While the gut endocrine cells have been described in several insect groups (Martoja \& BallanDufrancais 1982), their presence in the Hemiptera, and particularly in Rhodnius, has received little attention. In the anterior intestine of adult Rhodnius, the digestive epithelium consists of tall columnar cells (Billingsley \& Downe 1983), and the endocrine cells are similarly elongated along their perpendicular axes. In 2nd-instar nymphs, the digestive epithelium consists of flatter, columnar cells, and the associated endocrine cells are similarly flattened (Bauer 1981). No other differences between the endocrine cells of the 2 stages are obvious, suggesting that the changes in cell shape are a result of maturation in the adult rather than indicating any functional differences. Cassier \& FainMaurel (1977) examined the endocrine cells from several insect species, including Rhodnius, representing a number of insect orders. They stated that in all Pterygotes studied, endocrine cells were always associated with regenerative nests with up to 3 endocrine cells per nest, that endocrine cells became more concentrated towards the posterior of the gut, and that endocrine cells had the same char-

Fig. 1-3. 1, Single regenerative cell from the anterior intestine 5 days after blood feeding $(7,080 \times)$. 2, Paired regenerative cells from the anterior intestine before feeding; both cells rest on the basal lamina and are of approximately equal size $(6,940 \times) .3$, Paired regenerative cells from the an-

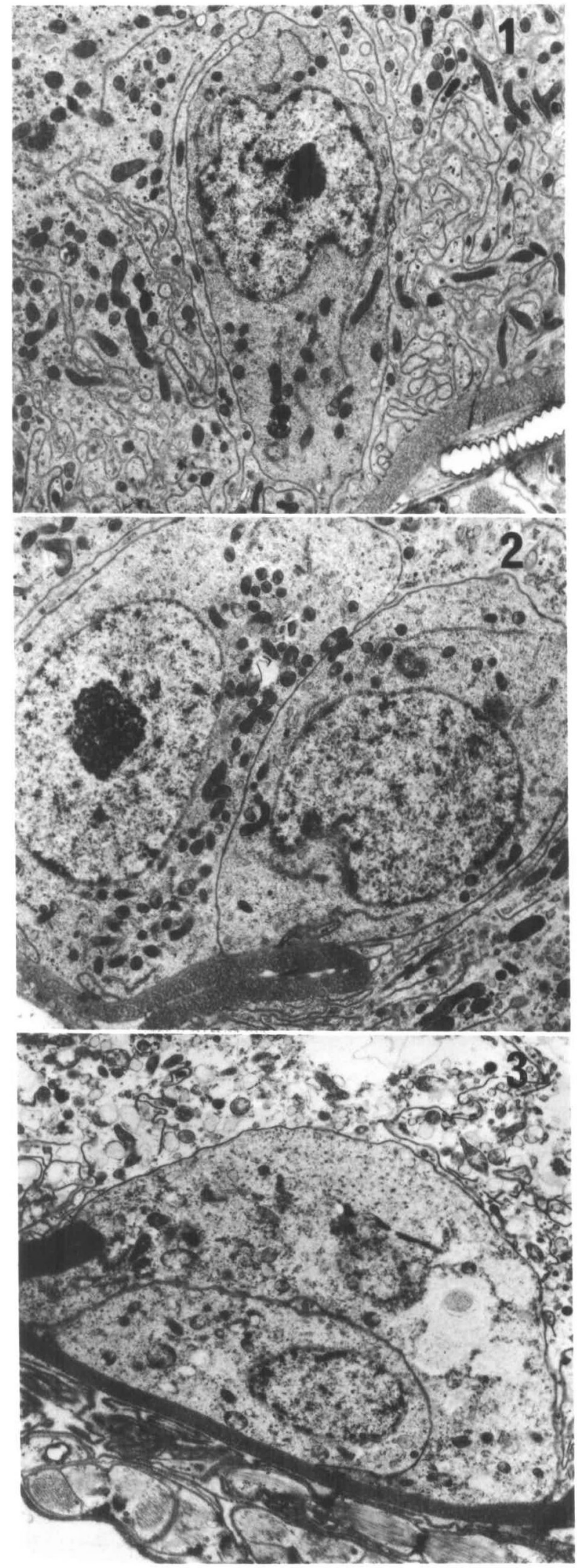

terior intestine 5 days after blood feeding; cells are not always of equal size and may display varied configurations $(5,900 \times)$. 


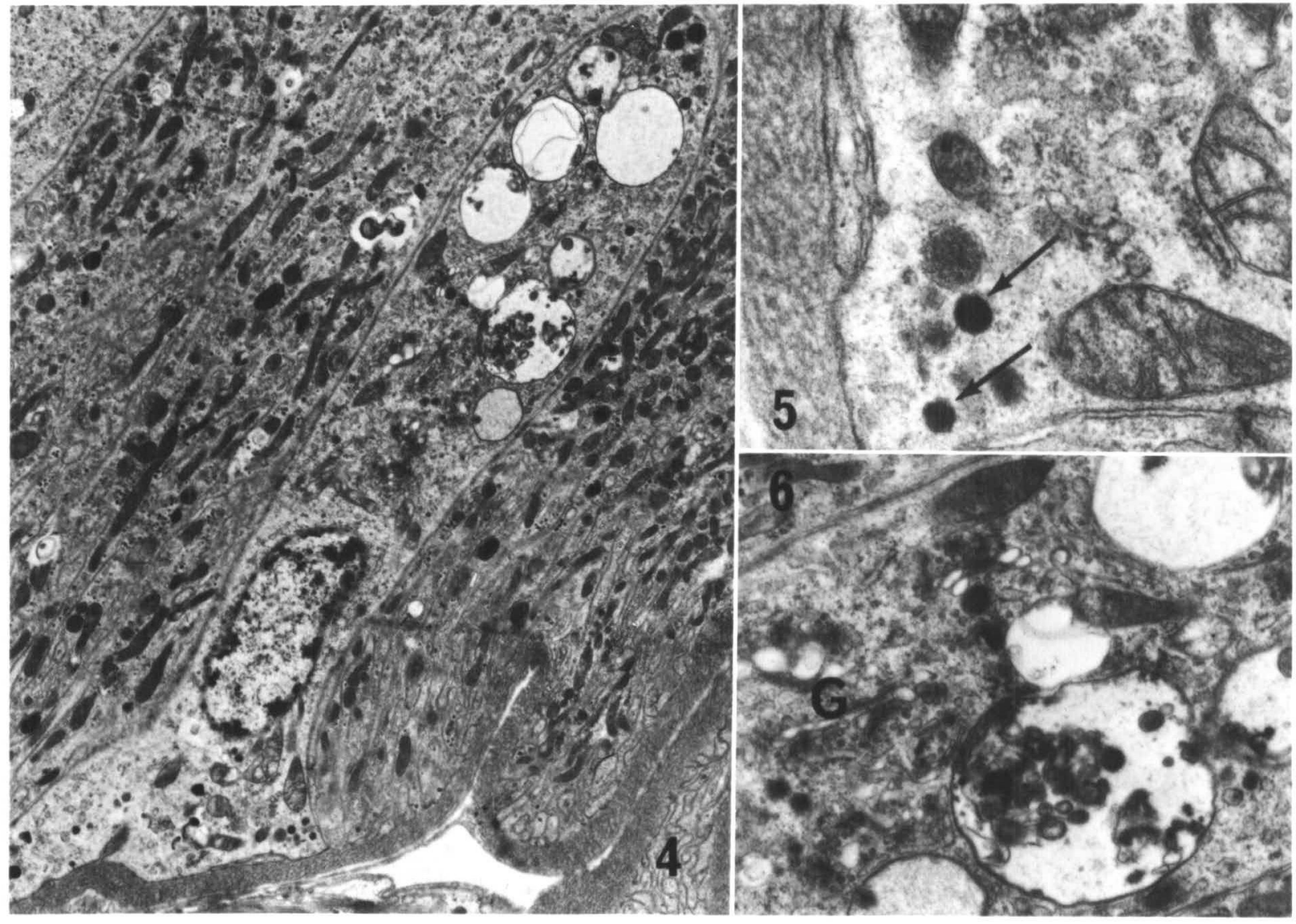

Fig. 4-6. 4, Gut endocrine cell from the anterior intestine 5 days after blood feeding; the cell displays characteristics typical of all gut endocrine cells observed (see text) $(5,920 \times)$. 5, Detail of the basal region of cell shown in Fig. 4; secretory vesicles (arrows) are present close to the basal plasma membrane $(34,300 \times) .6$, Detail of the apical region of the cell shown in Fig. 4; note several well-developed Golgi complexes $(G)$ and electronopaque vesicles containing membranous material $(15,300 \times)$.

acteristics at all postembryonic stages of development. This is clearly not the case with Rhodnius, in which regenerative cells rather than regenerative nests were present (Fig. 1-3). Endocrine cells were never observed in association with regenerative cells (Fig. 4) and were apparently restricted to the intestine, where they exhibited different morphological characteristics at different stages of development (Bauer 1981, present study). Unfortunately, Cassier \& Fain-Maurel (1977) did not publish any electron micrographs of Rhodnius endocrine cells, nor did they discuss results specific to their observations on the Rhodnius midgut. Therefore any direct comparison with their results is not possible.

There was little resemblance between the gut endocrine cells of Rhodnius and those from nonhemipteran hematophagous insects. In mosquitoes (Hecker 1977) and tsetse (Boehringer-Schweizer 1977), the gut endocrine cells have been described as "clear cells," while in fleas (Reinhardt 1976) and in Rhodnius the endocrine cells have a denser cytoplasm. Similarly, the gut endocrine cells described in other hematophagous insects are of the "open" type (Fujita \& Kobayashi 1977), having a lumenal surface with a variable brush border of microvilli; this is not the case with Rhodnius, in which the gut endocrine cells are of the "closed" type (Fujita \& Kobayashi 1977).

The gut endocrine cells of Rhodnius most closely resembled the pyramidal cells seen in the cockroach (Nishiitsutsuji-Uwo \& Endo 1981) and various lepidopteran species (Endo \& NishiitsutsujiUwo 1981). Up to 6 types of endocrine granules were identified in the cockroach, resulting in a classification of the various endocrine cells according to the type of granule present. These cell types displayed differential secretory activities (Endo \& Nishiitsutsuji-Uwo 1982). The secretory granules observed in Rhodnius resemble the type $\mathrm{I}-\mathrm{b}+\mathrm{c}$ 
granules of the cockroach, but there is not sufficient diversity in endocrine cell structure to warrant any attempt at such a classification.

Experimental evidence exists for control of digestive proteinases by both secretagogue (Briegel \& Lea 1975) and hormonal (Downe 1975; Briegel \& Lea 1979; Houseman \& Downe 1983) mechanisms in hematophagous insects, and gut endocrine cells may play one or more roles in the latter mechanism. Polypeptides analogous to active polypeptides from the mammalian gut have been demonstrated in the cockroach midgut by immunohistochemical techniques (Iwanaga et al. 1981). In mammals the gut endocrine cells are stimulated to secretion by stretching of the gut (Fujita \& Kobayashi 1977); similarly, in Rhodnius there is considerable stretching of the midgut during blood feeding. Secretion by the endocrine cells during feeding would allow activation of the hormonal control mechanism early in the digestive process. This would also explain why no secretion of the vesicles was observed in this study, as no insects were collected during blood feeding. Alternatively, the gut endocrine cells may be stimulated to secretion by some factor from the blood meal, and the secretion(s) could act either directly on the digestive cells of the midgut to regulate production of proteinases, or they might control release of a digestive-regulatory factor from some other tissue.

While the gut endocrine cells of insects in general offer some circumstantial evidence for the hormonal control of digestion, they have been inadequately studied. Because of the interrupted mode of feeding common in hematophagous insects, the midgut epithelium has developed into a highly inducible system, undergoing considerable modification in response to a blood meal (BoehringerSchweizer 1977; Hecker 1977; Billingsley \& Downe 1983). If the gut endocrine cells of hematophagous insects are involved in regulation of digestion, then these too will probably be induced to change by the blood meal. Clearly, further study on the timing of the release of secretory granules along with histochemical studies (Iwanaga et al. 1981) on the content of the secretory granules is required to elucidate the function of these cells.

Acknowledgments. We thank Mrs A.M. Hutchison and Mrs A. Svatek for technical assistance.

\section{LITERATURE CITED}

Anderson, E. \& W.R. Harvey. 1966. Active transport by the cecropia midgut. II. Fine structure of the midgut epithelium. J. Cell Biol. 31: 107-34.
Andries, J.C. 1982. L'intestin moyen des insectes. I. Origine embryologique et ultrastructure. Annee Biol. 2: 144-86.

Andries, J.C. \& G. Torpier. 1982. An extracellular brush border coat of lipid membranes in the midgut of Nepa cinerea (Insecta, Heteroptera): Ultrastructure and genesis. Biol. Cell 46: 195-202.

Baerwald, R.J. \& J.B. Delcarpio. 1983. Double membranebounded intestinal microvilli in Oncopeltus fasciatus. Cell Tissue Res. 232: 593-600.

Bauer, P. 1981. Ultrastrukturelle und physiologische Aspekte des Mitteldarms von Rhodnius prolixus Stal (Insecta, Heteroptera). Unpubl. Ph.D. thesis. University of Basel, Switzerland. $126 \mathrm{p}$.

Billingsley, P.F. \& A.E.R. Downe. 1983. Ultrastructural changes in posterior midgut cells associated with blood feeding in adult female Rhodnius prolixus Stal (Hemiptera: Reduviidae). Can. J. Zool. 61: 2574-86.

1985. Cellular localisation of aminopeptidase in the midgut of Rhodnius prolixus Stal (Hemiptera: Reduviidae) during blood digestion. Cell Tissue Res. 241: 421-28.

Boehringer-Schweizer, S. 1977. Digestion in the tsetse fly: An ultrastructural analysis of structure and function in Glossina morsitans morsitans (Machado) (Diptera, Glossinidae). Unpubl. Ph.D. thesis. University of Basel, Switzerland. $77 \mathrm{p}$.

Briegel, H. \& A.O. Lea. 1975. Relationship between protein and proteolytic activity in the midgut of mosquitoes. J. Insect Physiol. 21: 1597-1604.

1979. Influence of the endocrine system on tryptic activity in female Aedes aegypti. J. Insect Physiol. 25: 227-30.

Burgos, M.H. \& L.S. Gutierrez. 1976. The intestine of Triatoma infestans. I. The cytology of the midgut. J. Ultrastruct. Res. 57: 1-9.

Cassier, P. \& M.A. Fain-Maurel. 1977. Sur la presence d'un systeme endocrine diffus dans le mesenteron de quelques insectes. Arch. Zool. Exp. Gen. 118: 197-209.

Downe, A.E.R. 1975. Internal regulation of rate of digestion of blood meals in the mosquito, Aedes aegypti. J. Insect Physiol. 21: 1835-39.

Endo, Y. \& J. Nishiitsutsuji-Uwo. 1981. Gut endocrine cells in insects: The ultrastructure of the gut endocrine cells of the lepidopterous species. Biomed. Res. 2: 270-80.

1982. Exocytotic release of secretory granules in the midgut of insects. Cell Tissue Res. 222: 515-22.

Fujita, T. \& S. Kobayashi. 1977. Structure and function of gut endocrine cells. Int. Rev. Cytol. Suppl. 6: 187-233.

Gutierrez, L.S. \& M.H. Burgos. 1978. The intestine of Triatoma infestans. II. The surface coat of the midgut. $J$. Ultrastruct. Res. 63: 244-51.

Hecker, H. 1977. Structure and function of midgut epithelial cells in Culicidae mosquitoes (Insecta, Diptera). Cell Tissue Res. 184: 321-41.

Houseman, J.G. \& A.E.R. Downe. 1983. Activity cycles and the control of four digestive proteinases in the posterior midgut of Rhodnius prolixus Stal (Hemiptera, Reduviidae). J. Insect Physiol. 29: 141-48.

Iwanaga, T., T. Fujita, J. Nishiitsutsuji-Uwo \& Y. Endo. 1981. Immunohistochemical demonstration of PP-, somatostatin-, enteroglucagon- and VIP-like immunoreactivities in the cockroach midgut. Biomed. Res. 2: 202-07.

Kwan, L.R. \& A.E.R. Downe. 1977. The effects of 5-fluorouracil on reproduction in Rhodnius prolixus. J. Med. Entomol. 14: 270-75.

Lane, N.J. \& J.B. Harrison. 1979. An unusual cell surface modification: A double plasma membrane. J. Cell Sci. 39: 355-72.

Martoja, R. \& C. Ballan-Dufrancais. 1982. The ultrastructure of the digestive and excretory organs. p. 199-268. In: R.C. 
King \& H. Akai, eds., Insect ultrastructure. Vol. 2. Plenum Press, New York.

Nishiitsutsuji-Uwo, J. \& Y. Endo. 1981. Gut endocrine cells in insects: The ultrastructure of the endocrine cells in the cockroach midgut. Biomed. Res. 2: 30-44.

Pacheco, J. 1970. Ultraestructura del piloro de Rhodnius prolixus (Hemiptera, Reduviidae). Acta Biol. Venez. 7: 41-70.

Pacheco, J. \& M. Ogura. 1966. Ultraestructura del promesentario de Rhodnius prolixus Stal (Hemip.). Bol. Acad. Cienc. Fis. Mat. Nat., Caracas 26: 44-68.
Priester, W. de. 1971. Ultrastructure of the midgut epithelial cells in the fly Calliphora erythrocephala. J. Ultrastruc. Res. 36: 783-805.

Reinhardt, C.A. 1976. Ultrastructural comparison of the midgut epithelia of fleas with different feeding behaviour patterns (Xenopsylla cheopis, Echidnophaga gallinacea, Tunga penetrans, Siphonaptera, Pulicidae). Acta Trop. 33: 105-32.

Wigglesworth, V.B. 1943. The fate of haemoglobin in Rhodnius prolixus (Hemiptera) and other blood-sucking arthropods. Proc. R. Soc. Lond. Ser. B 131: 313-39.

\section{BOOK NOTICES}

\section{INTERNATIONAL CATALOG OF ARBOVIRUSES INCLUDING CERTAIN OTHER VIRUSES OF VERTEBRATES}

3rd edition. Edited by N. Karabatsos. 1985. Published for the Subcommittee on Information Exchange of the American Committee on Arthropodborne Viruses by the American Society of Tropical Medicine \& Hygiene, P.O. Box 29837, San Antonio, Texas 78229, USA. 1,147 p.

\section{A BIBLIOGRAPHY ON CHAGAS' DISEASE (1968-1984)}

Compiled by James A. Dvorak, Carter C. Gibson, and Alberto Mackelt. The result of cooperative effort by the U.S. National Institutes of Health, the Pan American Health Organization, and the World Health Organization. 1985. $397 \mathrm{p}$. 